\title{
Kebijakan Penentuan Pusat Pertumbuhan Industri Untuk Mendukung Pembangunan Daerah
}

\author{
1Yelly Zamaya, ${ }^{2}$ Dahlan Tampubolon \\ ${ }^{12}$ Fakultas Ekonomi dan Bisnis Universitas Riau \\ Email : yelly.zamaya@lecturer.unri.ac.id
}

\begin{abstract}
Abstrak
Penentuan pusat pertumbuhan ekonomi di suatu daerah merupakan topik yang perlu dikaji dan dipraktikkan untuk mendorong pembangunan ekonomi daerah. Pusat pertumbuhan, terintegrasi dengan sektor industri secara makro. Metode untuk menentukan pusat pertumbuhan industri meliputi: teknik analisis kebutuhan teknologi, analisis kesenjangan pencapaian dan target, penyusunan strategi untuk memenuhi kebutuhan dan pernyataan ketidakpastian yang akan datang. Hasil analisis menempatkan Bengkalis sebagai sentra produksi dan pertumbuhan industri di pesisir timur Riau bagian tengah. Kawasan Siak Kecil dan Bukit Batu menjadi pusat pertumbuhan industri untuk menunjang kegiatan di Dumai. Akses jalan dari kecamatan lain ke Buruk Bakul ditingkatkan untuk meningkatkan aksesibilitas. Pelabuhan di Buruk Bakul akan dibangun menjadi feeder port untuk pengiriman produk dari kawasan industri. Pusat pertumbuhan industri akan meningkatkan kualitas masyarakat lokal dan memastikan kondisi kehidupan yang berkelanjutan. Pengelompokan industri dapat meningkatkan pemanfaatan potensi pembangunan dan integrasi masyarakat lokal. Oleh karena itu, pusat pertumbuhan industri mendukung pengembangan modal sosial daerah dan kualitas hidup. Implementasi pusat-pusat pertumbuhan, melengkapi kesenjangan antara kebijakan pemerintah pusat dan provinsi serta masyarakat.
\end{abstract}

Kata Kunci : pusat pertumbuhan industri, produksi, aksesibilitas, masyarakat lokal, kebijakan pemerintah

\begin{abstract}
Determining the centre of economic growth in a region is a topic that needs to be studied and practised to encourage regional economic development. Growth centres, integrated with the industrial sector on a macro basis. Methods for determining the centre of industrial growth include: technology needs analysis techniques, analysis of achievement gaps and targets, preparation of strategies for meeting needs and statements of impending uncertainty. The analysis results put Bengkalis as the centre of production and industrial growth in the central part of the eastern coast of Riau. Siak Kecil and Bukit Batu areas have become industrial growth centres to support activities in Dumai. Road access from other sub-districts to Buruk Bakul is improved to improve accessibility. The port in Buruk Bakul will be build to become a feeder port for shipping products from industrial areas. Industrial growth centres will enhance the quality of local communities and ensure sustainable living conditions. Industrial grouping can increase the utilization potential of development and integration of local communities. Therefore, industrial growth centres support the development of regional social capital and quality of life. Implementation of growth centres, completing the gap between national and provincial government policies and the community.
\end{abstract}

Keywords: centre of industrial growth, production, accessibility, local communities, government policies

\section{PENDAHULUAN}

Pembangunan industri nasional bertujuan mendukung percepatan penyebaran pembangunan industri keluar pulau Jawa. Pembangunan industri juga bertujuan meningkatkan nilai tambah dan penyerapan tenaga kerja. Pembangunan industri harus mempertimbangkan keberadaan wilayah. Pembangunan daerah sebagai proses mengarahkan seluruh potensi wilayah dimanfaatkan secara terpadu guna mewujudkan kesejahteraan masyarakat dan menanggulangi daerah tertinggal. 
Industri makin penting perannya dan patut untuk dijadikan penopang utama ekonomi nasional (Pinem, 2016). Penentuan pusat pertumbuhan ekonomi suatu daerah menjadi topik yang perlu dikaji dan dipraktikkan guna mendorong pembangunan ekonomi daerah. Teori kutub pertumbuhan mendasarkan gagasannya tentang peran utama industri dalam menciptakan barang dan jasa baru secara dinamis. Sentra dan kawasan ekonomi yang menampung usaha-usaha industri unggulan menjadi kutub penarik faktor produksi, karena paling efektif dalam pemanfaatannya (Pidgrushny, 2013). Pengembangan klaster industri akan menarik penanaman modal dan mendorong penciptaan kesempatan kerja (Hunter \& Saldana, 2013).

Kebijakan pemerintah memanfaatkan lahan sebagai kawasan industri menjadi penting (Yang et al., 2016). Melalui RIPIN tersebut pemerintah telah menetapkan Wilayah Pusat Pertumbuhan Industri (WPPI) sebagai rencana penting pembangunan industri nasional. WPPI Riau adalah salah satu dari 22 (dua puluh dua) WPPI yang telah ditetapkan. WPPI Riau mencakup Dumai, Siak, dan Bengkalis. Dalam Peraturan Daerah Provinsi Riau Nomor 9 tahun 2018 tentang Rencana Pembangunan Industri Provinsi (RPIP), maka kedepan dalam mendorong pertumbuhan pembangunan industri, termasuk di wilayah Kabupaten Bengkalis.

Pertumbuhan industri memiliki pengaruh positif dan negatif dalam kehidupan manusia. Efek positifnya, industri dapat memberikan banyak kesempatan kerja bagi semua elemen masyarakat. Dampak negatifnya adalah pertumbuhan industri membutuhkan area untuk beroperasi dan area strategis biasanya area pertanian. Meskipun sektor industri memiliki manfaat dalam menunjang perekonomian, namun harus diperhatikan harus berdampak pada sektor pertanian yang menyediakan pangan bagi kehidupan manusia (Rozaki, 2020). Kebijakan penentuan kawawan industri menyebabkan struktur dan pola keruangan kekurangan lahan pertanian, kemacetan, dan penurunan kualitas hidup (Qiu et al., 2015). Konversi lahan secara masiv pada tahun 2017 akibat penetapan wilayah pusat pertumbuhan industri dan wilayah sekitar lokasi (Paramasatya \& Rudiarto, 2020)

Dalam konteks pembangunan daerah, klaster regional dianggap sebagai landasan inisiatif inovasi pembangunan daerah yang berkelanjutan. Ini akan menjadi tantangan penting untuk menilai kinerja berbagai klaster. Klaster begitu penting diukung modal sosial di daerah dikombinasikan dengan spesialisasi teknologi produksi untuk pencapaian pusat pertumbuhan yang tinggi. Kondisi seperti itu memberikan keuntungan jaringan yang dihasilkan oleh sinergi antara kelompok industri. Klaster industri akan berbeda ciri nya di setiap wilayah dalam satu negara sesuai dengan keberagaman wilayah yang ada (Gonzalez et al., 2017).

Strategi pembangunan daerah di masa depan sangat bergantung atas kemampuan daerah mengatur diri sendiri. Strategi ini melalui kombinasi cerdas dari sumber daya lokal, mengembangkan aksi operasional yang berkelanjutan, dan berwawasan ke depan. Perspektif baru tentang sumber daya sebagai pendukung pertumbuhan daerah tidak diragukan lagi akan menjadi kajian dalam pembangunan daerah (Nijkamp, 2016).

Untuk mendukung pembangunan di daerah, disusun WPPI Bengkalis yang mencakup analisis kebutuhan infrastruktur. Meliputi prasarana, informasi dan telekomunikasi, supply dan akses energi, ilmu pengetahuan dan teknologi, sumberdaya manusia, kelembagaan dan regulasi/kebijakan. Hal itu untuk mempercepat pengembangan industri di Bengkalis dan mendukung konektivitas antara pusat pertumbuhan ekonomi dengan wilayah belakangnya sehingga terjadi efek penyebaran pertumbuhan (spread effect). Sehingga pembangunan pusat pertumbuhan industri secara kewilayahan terintegrasi dengan pembangunan sektor industri secara makro. 


\section{METODE}

Hal yang menjadi dasar dalam metode penentuan pusat pertumbuhan industri antara lain :

1) Menggunakan teknik analisis kebutuhan teknologi;

2) Mengakomodasikan konsep-konsep terkini terikait pembangunan sektor industri, infrastruktur, serta pembangunan wilayah;

3) Mengidentifikasikan kebutuhan wilayah industri dengan analisis gap keadaan di wilayah Bengkalis dengan target pembangunan WPPI, serta melakukan verifikasi rencana pembangunan yang siap dilaksanakan;

4) Mengakomodasi konsep pembangunan wilayah industri terpadu merangkumi infrastruktur transportasi, telekomunikasi, sumber daya air, energi, SDM dan teknologi terkait lainnya dalam konteks WPPI;

5) Menggunaakan metode strategi pemenuhan kebutuhan infrastruktur dan teknologi untuk pengembangan WPPI secara sistematis;

6) Mengakomodasikan identifikasi terhadap berbagai ketidakpastian yang akan dihadapi dalam proses pembangunan.

Langkah pertama yang dilakukan dalam penyusunan WPPI Kabupaten Bengkalis adalah menentukan jenis data yang digunakan. Data primer diperoleh dari Focus Group Discussion (FGD) dengan pemangku kepentingan untuk memperoleh data kualitatif dan data kuantitatif berkenaan dengan pengembangan wilayah industri. Data sekunder dikumpulkan dari instansi dan dokumentasi lainnya. Overlay peta juga dilakukan untuk menentukan wilayah industri (Rianto \& Santoso, 2018). Jacob dan Hasan (2016) menggunakan scalogram dengan menetapkan hirarki setiap wilayah selanjutnya ditentukan berdasarkan jumlah total fasilitas yang tersedia di wilayah.

Sejumlah besar ilmuwan menganggap e-governance sebagai faktor utama dalam meningkatkan sistem penyampaian layanan negara. Pemerintah turut mensosialisasikan agar dapat diadopsi dalam implementasi pembangunan wilayah. Di dalam pengembangan pusat pertumbuhan industri, faktor egovernment diperlukan dan diadopsi untuk penyusunan keputusan (Munyoka \& Maharaj, 2017).

Untuk mengidentifikasi wilayah pertumbuhan ekonomi regional dianalisis, dievaluasi, dan diklasifikasikan menurut pangsa relatif industri dalam total output yang dihasilkan di wilayah tersebut bunga; dengan bagian relatif dari bisnis yang tidak menguntungkan di industri; dengan tingkat profitabilitas industri (barang) dan dengan nilai moneter dari keuntungan yang diperoleh industri. Prosedur untuk mengklasifikasikan cabang telah diajukan untuk tujuan mengidentifikasi area pertumbuhan ekonomi dengan totalitas bisnis terkemuka dan kinerja fiskal (ukuran pembayaran pajak) industri. Terbukti bahwa perkembangan ekonomi industri kawasan yang maju dimungkinkan sebagai hasil dari intensifikasi kawasan kutub pertumbuhan, dengan prioritas proyek-proyek inovatif dan investasi untuk pengembangan lokomotif cabang-cabang regional yang berfungsi sebagai kawasan pertumbuhan utama ekonomi daerah (Pysar, 2017).

\section{HASIL DAN PEMBAHASAN}

\section{Kebijakan Polarisasi dan Integrasi Ruang Ekonomi}

Kutub pertumbuhan merupakan teori utama yang memprakarsai penyebaran pembangunan. Implementasi prkatisnya digunkan dalam pengembangan berbagai strategi pertumbuhan wilayah. ekonomi nasional. Penciptaan kutub pertumbuhan berkontribusi untuk mengatasi masalah seperti pembangunan wilayah tertinggal. Seperti membentuk industri dan struktur ekonomi spasial, 
meningkatkan daya tarik investasi negara, mengembangkan industri padat pengetahuan, mengintensifkan proses inovasi, meminimalkan transportasi dan biaya lainnya.

Konsep ini secara aktif didorong oleh para ahli Barat untuk berkembang dalam bentuk berbagai proyek investasi. Selain itu, ada kebutuhan mendesak dalam realitas ekonomi saat ini untuk membentuk strategi yang jelas bagi pembangunan ekonomi, mengidentifikasi cabang lokomotif ekonomi nasional yang menjanjikan, dan mengatasi disproporsi dalam pembangunan sosial ekonomi dan regional, yang semakin parah. Untuk mengatasi masalah inilah teori kutub pertumbuhan harus diterapkan (Harus \& Zhuravliov, 2015).

Oleh karena itu, perlu diperjelas kinerja daftar fungsi daerah prioritas dan memungkinkan tercapainya tujuan pembangunan sosial ekonomi daerah dalam perspektif strategis sebagai bagian dari penelitian yang diperlukan dalam rangka perluasan dan pendalaman pembangunan. proses globalisasi dan transformasi ekonomi.

Perroux (1970) menyusun klasifikasi industri menurut tren pembangunan, dan membaginya menjadi tiga kelompok:

a. industri yang menampilkan perkembangan lambat, degradasi, rentan terhadap penurunan konstan dalam hal bagiannya dalam struktur ekonomi negara (wilayah);

b. industri yang memiliki tingkat pertumbuhan tinggi tanpa pengaruh yang signifikan terhadap perkembangan cabang ekonomi lainnya;

c. industri yang tidak hanya menunjukkan pertumbuhan yang cepat, tetapi juga menghasilkan reaksi berantai yang mengakibatkan munculnya dan pertumbuhan pusat-pusat industri dan perkembangan industri umum di negara tersebut.

Perroux juga menekankan bahwa pertumbuhan tidak terjadi di mana-mana dan sekaligus, melainkan meningkat di daerah atau kutub pertumbuhan dan menyebar melalui saluran yang berbeda, menyebabkan hasil yang berbeda (Karmyshev, 2005). Studi yang menggunakan kriteria khusus industri memberikan gambaran tentang ruang lingkup aktivitas di mana pembangunan dapat terjadi, seseorang tidak dapat mengabaikan peluang munculnya apa yang disebut area spontan (kutub pertumbuhan), yang inovatif di alam. Dalam kajian ini, industri pertambangan dengan potensi energinya untuk pengembangan wilayah dan sumber daya cadangan disarankan sebagai tiang pertumbuhan (Lyashenko, 2015).

Jika wilayah pertumbuhan wilayah diintensifkan, hal ini akan memungkinkan munculnya jenis kegiatan baru yang mampu:

a. mendiversifikasi dan merasionalisasi struktur ekonomi kawasan dalam jangka panjang;

b. meningkatkan kualitas hidup dan kegiatan ekonomi penduduk;

c. mendorong penguatan dan pengembangan hubungan ekonomi antardaerah dan luar negeri;

d. mendorong munculnya dan perluasan spektrum sumber pembiayaan proses investasi dengan meningkatkan daya tarik investasi daerah;

e. meningkatkan kualitas hidup dan kegiatan ekonomi penduduk;

f. menyediakan pendapatan anggaran yang cukup untuk membiayai lingkungan sosial kawasan (Lyashenko, 2015).

Dalam mengejar keunggulan kompetitif jangka panjang, entitas utama integrasi industri terdiri dari perusahaan dan grup besar ( $\mathrm{Lu}, 2017)$. Agregasi regional dan agregasi industri merupakan fondasi ekonomi yang obyektif bagi perkembangan ekonomi daerah dan pembentukan kota. Teori integrasi dan perkembangan industri regional dan dampak dari faktor-faktor tersebut, mekanisme dinamis dan mekanisme integrasi interaktif yang muncul dinyatakan dan dijelaskan. Karena faktor pengaruh yang berbeda mengarah pada pola integrasi yang berbeda, maka perlu untuk secara teoritis menguraikan hubungan internal dan jalur yang berpengaruh dari faktor dan pilihan yang relevan atas integrasi dan kerja sama industri regional, memungkinkan entitas ekonomi untuk melakukan pengambilan keputusan yang lebih tepat (Han, 2018). 
Mengembangkan produksi industri ke depan adalah terkait dengan peningkatan investasi di industri daerah. Perlu dikembangkan cara untuk menarik investor menciptakan industri berteknologi tinggi. Ini akan memungkinkan peningkatan pemrosesan bahan mentah, pengorganisasian industri berteknologi dan pengembangan produksi pertanian ke tingkat yang baru. Penting bagi pejabat daerah untuk menyadari perlunya menyelesaikan masalah-masalah ini di daerah. Masalah ini juga menjadi masalah nasional. Tugas pertama dan terpenting pejabat daerah adalah meningkatkan kapasitas daerah termasuk pengelolaan sumber daya alam, tenaga kerja dan ekonominya (Lapaeva \& Lapaev, 2020).

Peran pemerintah dalam membuat pusat pertumbuhan sangat penting. Klaster industri yang mendukung pertumbuhan akan lebih siap dibuat jika ada dukungan finansial dan kelembagaan dari pemerintah. Klaster industri yang hendak dibuat harus diawali dengan penetapan hierarki untuk perwilayahan industri. Adapun hirarki tersebut adalah Wilayah Pusat Pertumbuhan Industri (WPPI), kemudian Kawasan Peruntukan Industri (KPI) dan Kawasan Industri (KI). Tujuan utama dibentuknya WPPI adalah untuk mengakomodir wilayah Indonesia yang luas dengan memperhatikan potensi sumber daya alam dan sumber daya manusia yang tersedia di wilayah. WPPI ini sudah diatur didalam undangundang Republik Indonesia No. 3 Tahun 2014 tentang Perindustrian.

Setiap WPPI yang dibentuk peran pemerintah daerah sangat besar dalam hal mendorong perkembangan kawasan industri. Pemerintah menjadi penggerak utama untuk mengembangkan kawasan industri sebelum pihak swasta mampu atau berminat untuk mengembangkannya. Hal ini bisa menciptakan peran pemerintah untuk menyediakan fasilitas, sarana dan prasarana di kawasan industri tersebut. Dari berkembannya kawasan industri sebagai pusat inti pertumbuhan pada setiap WPPI, maka tidak akan dipungkiri pula akan berkembangnya sentra industri kecil dan industri menengah pada kawasan tersebut. Efek ini diharapkan mampu sebagai penggerak perekonomian daerah di setiap adanya WPPI.

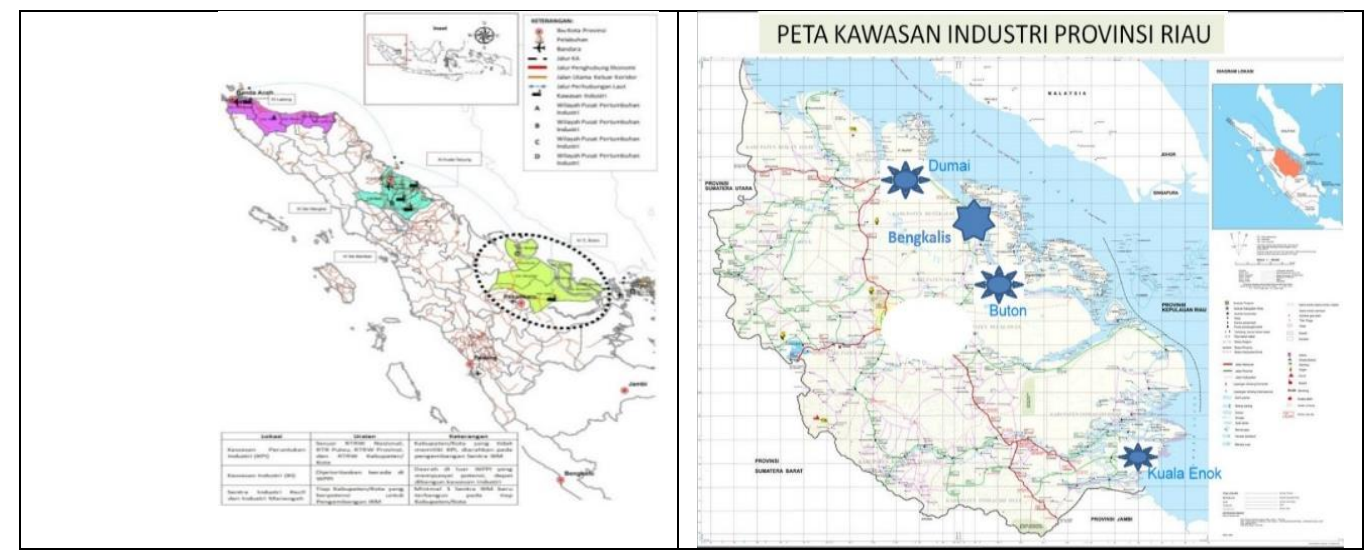

Gambar 1: Rencana Pusat Pertumbuhan Industri di Riau

Dibentuknya WPPI dan atau pusat-pusat pertumbuhan yang ada di Indonesia bertujuan untuk meratakan pertumbuhan ekonomi diseluruh wilayah. Untuk mencapai pemerataan tersebut berbagai kajian harus dilakukan agar keinginan pusat pertumbuhan selalu menjadi bagian dari pembangunan nasional. Setiap daerah harus memiliki rencana tata ruang yang disusun berdasarkan undang-undang No.26 Tahun 2007 tentang Penataan Ruang. Saat ini di dalam rencana tata ruang semua daerah telah memasukan terminologi pusat pertumbuhan.

\section{Kebijakan Pertumbuhan Industri Di Kabupaten Bengkalis}

Di dalam konsep pusat pertumbuhan, wilayah dilihat sebagai suatu kawasan yang memiliki sejumlah integral tertentu, karakteristik yang saling terkait, sehingga dapat dibedakan dari wilayah lain. Memastikan perkembangan ekonomi wilayah dinyatakan dalam pendapatan per kapita. Pada kondisi 
kurangya tabungan masyarakat dimungkinkan untuk mendukung proses investasi dan reproduksi modal, sehingga mendorong pertumbuhan ekonomi.

Pemanfaatan sumber daya alam, sumber daya manusia, sumber daya teknologi, sumber daya kelembagaan, infrastruktur fisik, sarana dan prasarana yang dilakukan secara optimal, efektif, efisien dan berkelanjutan dalam pembangunan wilayah industri, hal ini dapat meningkatkan kesejahteraan rakyat. Adapun tujuan dari pemanfaatan tersebut untuk menciptakan daerah-daerah di Indonesia agar dapat berkembang secara bersama-sama yang mana dapat mengurangi atau menghilangkan kesenjangan antar daerah.

Beberapa kawasan peruntukan industri dan sentra industri kecil dan menengah (SIKIM) di Riau rencana akan dikembangkan di beberapa pusat pertumbuhan. Rencana Sikim Bengkalis hampir tersebar di setiap kecamatan dengan sentra di Bengkalis. Rencana Sikim Siak berada tersebar di setiap kecamatan dengan sentra Kecamatan Tualang. Rencana Sikim Dumai tersebar di setiap kecamatan dengan pusat Kecamatan Dumai Barat. Rencana Sikim Indragiri Hilir yang terpusat di Kuala Enok dan tersebar hampir di semua kecamatan.

Menurut undang-undang No. 4 Tahun 2014 tentang perindustrian, dinyatakan bahwa sarana dan prasarana industri yang merupakan bagian dari lokasi industri harus tersedia secara spesifik. Dalam undang-undang tersebut menyatakan bahwa sarana dan prasarana industri berupa standarisasi dan prasarana. Parasarana tersebut berupa lahan, energi dan listrik, telekomunikasi, sumber daya air, sanitasi, dan jaringan transportasi. Tersedianya sarana dan prasarana industri mampu menciptakan konfigurasi lainnya yang menjadi daya tarik bagi industri untuk dapat masuk dan berkembang di kawasan tersebut. Penyediaan infrastruktur, sarana dan prasarana untuk industri akan sangat berdampak apabila dibarengi dengan peraturan dan birokrasi pemerintah yang kondusif bagi industri tersebut. Kolaborasi antara penyediaan infrastruktur dan birokrasi yang optimal akan membuat suatu kawasan industri semakin berkembang baik.

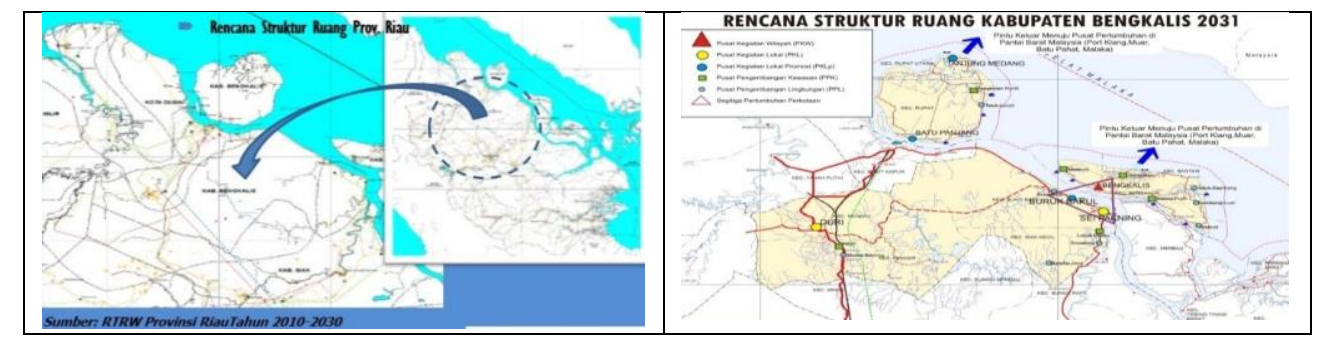

Gambar 2: Rencana Struktur Ruang Wilayah Kabupaten Bengkalis, 2020

Pengembangan sektor teknologi tinggi adalah cara yang mungkin untuk memperkuat posisi bersaing. Klaster dicirikan oleh entitas dan institusi yang sangat inovatif, terutama karena kondisi spesifik dari sektor teknologi tinggi dan lingkungan yang diciptakan. Dengan berpartisipasi dalam cluster proyek memenuhi SDGs (Szewrański et al., 2019), meningkatkan pengaruhnya pada pasar internal dan eksternal (Derlukiewicz et al., 2020).

Secara kelembagaan dapat menjadi faktor pendorong dan penghambat sedangkan faktor pendorong pembangunan wilayah ini adalah pembangunan fisik dan investasi. Selama ini pendidikan, kesehatan, prasarana dan sarana dan prasarana ekonomi telah mendorong pembangunan daerah, meskipun ada beberapa yang belum terlaksana, seperti sarana kesehatan dan ekonomi. Investasi menjadi pendorong pembangunan daerah karena terdapat investasi jangka panjang. Kebijakan rencana detil tata ruang (RDTR) sudah ada tetapi belum dilaksanakan, pola perdagangan masih didominasi oleh pertanian dan perkebunan namun terdapat peluang kegiatan perdagangan (Rahayu et al., 2019). 
Sektor industri pengolahan pada tahun 2019 memberikan kontribusi yang paling tinggi diantara sektor ekonomi lainnya pada perhitungan PDRB. Distribusi persentase terdapat PDRB sektor ini adalah 25,46\% dengan laju pertumbuhan 5,90\%. Ketergantungan Provinsi Riau terhadap sektor pertambangan dan penggalian harus segera digantikan dengan pengembangan sektor lain, diantaranya adalah sektor industri pengolahan ini. Hal ini dipicu oleh terus turunnya laju pertumbuhan dari sektor pertambangan selama beberapa tahun.

Tabel 1. Laju Pertumbuhan dan Distribusi Persentase Produk Domestik Regional Bruto Atas Dasar Harga Konstan 2010 Menurut Lapangan Usaha di Provinsi Riau (persen) Tahun 2019

\begin{tabular}{|c|c|c|c|c|c|}
\hline & \multirow[b]{2}{*}{ Lapangan Usaha } & \multicolumn{2}{|c|}{ Provinsi Riau } & \multicolumn{2}{|c|}{ Kabupaten Bengkalis } \\
\hline & & $\begin{array}{l}\text { Pert. } \\
(\%)\end{array}$ & $\begin{array}{l}\text { Distribusi } \\
(\%)\end{array}$ & $\begin{array}{c}\text { Pert. } \\
(\%)\end{array}$ & $\begin{array}{l}\text { Distribusi } \\
(\%)\end{array}$ \\
\hline A & Pertanian, Kehutanan, dan Perikanan & 4,12 & 23,18 & 5,47 & 9,35 \\
\hline $\mathrm{B}$ & Pertambangan dan Penggalian & $-6,93$ & 24,23 & $-6,95$ & 65,15 \\
\hline $\mathrm{C}$ & Industri Pengolahan & 5,90 & 25,46 & 6,05 & 13,10 \\
\hline $\mathrm{D}$ & Pengadaan Listrik dan Gas & 14,02 & 0,07 & 2,65 & 0,03 \\
\hline $\mathrm{E}$ & $\begin{array}{l}\text { Pengadaan Air, Pengelolaan Sampah, Limbah dan } \\
\text { Daur Ulang }\end{array}$ & 1,94 & 0,01 & 2,32 & 0,01 \\
\hline $\mathrm{F}$ & Konstruksi & 6,27 & 9,50 & 5,63 & 2,99 \\
\hline $\mathrm{G}$ & $\begin{array}{l}\text { Perdagangan Besar dan Eceran; Reparasi Mobil dan } \\
\text { Sepeda Motor }\end{array}$ & 5,13 & 10,73 & 5,11 & 6,48 \\
\hline $\mathrm{H}$ & Transportasi dan Pergudangan & 0,97 & 0,90 & 3,97 & 0,26 \\
\hline I & Penyediaan Akomodasi dan Makan Minum & 2,54 & 0,55 & 2,25 & 0,27 \\
\hline $\mathbf{J}$ & Informasi dan Komunikasi & 9,30 & 0,75 & 8,94 & 0,34 \\
\hline $\mathrm{K}$ & Jasa Keuangan dan Asuransi & 0,17 & 0,90 & 0,20 & 0,26 \\
\hline $\mathrm{L}$ & Real Estat & 5,34 & 0,90 & 6,30 & 0,28 \\
\hline $\mathrm{M}, \mathrm{N}$ & Jasa Perusahaan & 6,54 & 0,01 & 3,30 & 0,00 \\
\hline $\mathrm{O}$ & $\begin{array}{l}\text { Administrasi Pemerintahan, Pertahanan dan Jaminan } \\
\text { Sosial Wajib }\end{array}$ & 2,79 & 1,49 & 3,64 & 0,83 \\
\hline $\mathrm{P}$ & Jasa Pendidikan & 6,60 & 0,55 & 5,71 & 0,30 \\
\hline Q & Jasa Kesehatan dan Kegiatan Sosial & 10,69 & 0,21 & 6,89 & 0,09 \\
\hline $\mathrm{R}, \mathrm{S}, \mathrm{T}, \mathrm{U}$ & Jasa lainnya & 8,75 & 0,56 & 9,49 & 0,26 \\
\hline
\end{tabular}

Sumber : Badan Pusat Statistik, 2020

Kabupaten Bengkalis memiliki sektor pertambangan yang menjadi tumpuan sejak lama untuk membangun perekonomian daerah. Pada tabel di atas dapat dilihat bahwa sektor pertambangan Penggalian memberikan sumbangan terbesar dalam PDRB kabupaten mencapai 65,15\%. Sayangnya meskipun kontribusinya paling besar, tetapi laju pertumbuhannya terus menerus turun. Pada tahun 2019 laju pertumbuhan dari sektor pertambangan dan penggalian adalah -6,95\%.

Saat ini fokus pemerintah Kabupaten Bengkalis adalah pengembangan sektor Industi Pengolahan. Sarana dan prasarana penunjang perkembangan sektor industri pengolahan terus dilakukan. Pada tahun 2019 sektor ini memberikan kontribusi terhadap PDRB sebesar 13,10\% dimana laju pertumbuhannya $6,05 \%$.

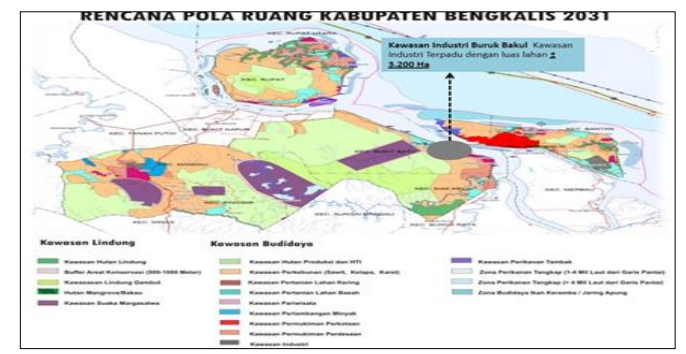

Gambar 3: Rencana Pola Ruang Kabupaten Bengkalis 2031 
Untuk menunjang fokus pemerintah tersebut empat pusat pertumbuhan baru di Kabupaten Bengkalis telah dibentuk. Empat kawasan tersebut adalah Kawasan Duri, Pulau Rupat, Bukit Batu dan Siak Kecil (termasuk Buruk Bakul) dan Pulau Bengkalis sebagai pusat pemerintahan. Kebijakan pusat pertumbuhan industri di Kabupaten Bengkalis bersinergi dengan adanya jalan tol Pekanbaru - Dumai. Pintu akses keluar dan masuk tol beberapa bagian merupakan kawasan yang terintegrasi dengan pusat pertumbuhan di Bengkalis, meliputi pintu Kandis, Duri Selatan dan Duri Utara. Pintu akses Kandis menghubungkan ke kawasan Perawang sebagai pusat kegiatan lokal (PKL). Pintu Duri sebagai bagian dari pusat kegiatan wilayah (PKW) Kabupaten Bengkalis dan Kabupaten Siak. Kesemua akses pintu tol yang ada menuju pelabuhan yang ada di Kota Dumai sebagai Pusat Kegiatan Nasional (PKN) yang ada di Riau.

Untuk mendukung pusat pertumbuhan wilayah, rencana pengembangan kereta api juga disusun bersinergi dengan pelabuhan ekspor di Dumai. Rencana pengembangan jalan kereta api di Provinsi Riau mencakup pengembangan trunk line (jalur utama) dan feeder (jalur lokal). Jalur utama dari jalur kereta api tersebut adalah antara Prapat - Duri - Dumai $(327 \mathrm{~km})$, Duri - Pekanbaru (124 km), Pekanbaru Muara Lembu $(161 \mathrm{Km})$ dan Muara Lembu - Teluk Kuantan - Muaro (138 km).

Arahan untuk lokasi-lokasi pelabuhan laut (umum) di WPPI Riau berdasarkan RTRWP Riau beberapa diantaranya merupakan pelabuhan baru, yaitu Lubuk Gaung (Pelabuhan Pengumpan Regional yang terdapat di Kota Dumai yang mana dalam jangka menengah/panjang dapat ditingkatkan menjadi Pelabuhan Nasional apabila Pelabuhan Dumai mulai penuh). Sei Pakning-Buruk Bakul (Pelabuhan Nasional) dan Selat baru (Pelabuhan Regional) yang terdapat di Kabupaten Bengkalis, dan Tanjung Buton (Pelabuhan Nasional, pindahan dari Pelabuhan Pekanbaru dalam jangka menengah/panjang memnungkinkan sebagai pelabuhan internasional) yang terletak di Kabupaten Siak.
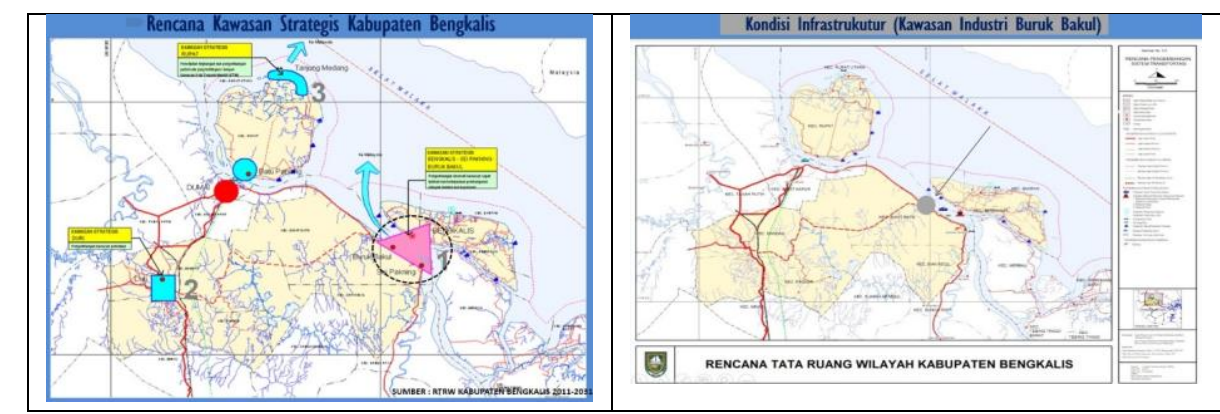

\section{Gambar 4: Rencana Pusat Pertumbuhan Industri Kabupaten Bengkalis}

Untuk pengembangan transportasi lokal di Bengkalis, berbagai poros transportasi dibentuk. Poros transportasi tersebut adalah Poros Transportasi Utara-Selatan dan Poros Transportasi Barat-Timur. Poros Transportasi Utara-Selatan untuk menghubungkan pergerakan transportasi dari Duri (Kecamatan Mandau) - Buruk Bakul (Kecamatan Bukit Batu) - Perkotaan Bengkalis - Selat Baru - Dermaga penyeberangan menuju Muar. Pergerakan Duri - Buruk Bakul dilakukan dengan memanfaatkan jalur darat melalui jaringan jalan baru Duri - Sei Pakning, Buruk Bakul - Bengkalis dilakukan dengan memanfaatkan jasa penyeberangan Ro-Ro Sei Selari - Air Putih, sedangkan dari Bengkalis ke dermaga penyeberangan di Kecamatan Bantan dilakukan melalui jalur darat Bengkalis - Selat Baru - Dermaga Penyeberangan.

Poros Transportasi Barat - Timur dikembangkan sebagai penghubung Tanjung Medang di Rupat Utara. Poros Barat - Timur ini mencakup pergerakan dari Tanjung Medang - Perkotaan Bengkalis Ketam Putih (di Pulau Bengkalis). Diharapkan poros Barat - Timur dapat meningkatkan aksesibilitas Pulau Rupat dan Pulau Bengkalis melalui fery penyeberangan. 
Fokus rencana kawasan industri di Kabupaten Bengkalis terletak di Kawasan Industri Buruk Bakul. Wilayah ini dilalui oleh jalan provinsi lintas Pekanbaru-Siak-Dumai. Pada tahap selanjutnya akan dibangun laluan Buruk Bakul-Duri sebagai penunjang kawasan. Selain itu akan direncanakan pula pendirian Pelabuhan Kelas Nasional. Untuk sarana air bersih pada kawasan ini masih dalam tahap perencanaan juga karena saat ini masyarakat masih memanfaatkan air sungai sebagai penunjang kehidupan sehari-hari.

Pada pembentukan pusat-pusat pertumbuhan yang telah direncanakan, tak terkecuali di Kabupaten Bengkalis tidak dapat dipisahkan satu sama lainnya. Pusat-pusat pertumbuhan tersebut akan saling berinteraksi agar tujuan mensejahterakan masyarakat dapat tercapai. Selain itu peran dari perguruan tinggi, pihak swasta atau industri, dan pemerintah adalah kunci inovasi dan pembangunan di era ekonomi berbasis sains dan ekonomi kreatif saat ini. Oleh karena itu, perlu diciptakan inovasi yang menjamin keterkaitan antar pusat pertumbuhan melalui pengembangan jaringan bisnis yang terintegrasi (Darmansyah et al., 2014).

Kabupaten Bengkalis mengarahkan kebijakan pembangunan daerah yang berorientasi agroindustri. Kebijakan agroindustri ini melibatkan berbagai program dan proyek lintas sektoral dan lintas wilayah. Untuk itu koordinasi dan kerjasama antar program dan proyek lintas sektor dan wilayah tetap harus mendapat prioritas dalam pelaksanaannya. Kebijakan pembangunan daerah ditetapkan untuk mewujudkan upaya peningkatan kualitas pelayanan publik dan dalam rangka percepatan pembangunan daerah yang mampu mendukung pertumbuhan ekonomi serta kelestarian lingkungan.

\section{KESIMPULAN}

Analisis visual memiliki sifat yang sedikit berbeda dari prosedur statistik klasik. Analisisnya didasarkan pada pemetaan data, ekstraksi berulang, dan umpan balik dari FGD. Kesimpulan diambil dari evaluasi pola, tren dan kebijakan pemerintah, baik pusat maupun daerah. Studi kami memanfaatkan peta hasil RTRW dan rencana pengembangan industri yang dikembangkan untuk mempersingkat waktu pembuatan keputusan, mengurangi ketidakpastian, dan memfasilitasi perencanaan berbasis pengetahuan. Data diintegrasikan sehingga pembaca dapat melakukan analisisnya sendiri atas apa yang kami sajikan. Hasil analisis memperkuat posisi Bengkalis sebagai pusat pertumbuhan produksi dan industri di bagian tengah pesisir timur Riau. Wilayah Siak Kecil dan Bukit Batu menjadi pusat pertumbuhan industri mendukung kegiatan di Dumai. Akses jalan dari kecamatan lain menuju Buruk bakul ditingkatkan untuk meningkatkan aksesibilitas. Pelabuhan di Buruk Bakul digesa menjadi pelabuhan pengumpan untuk mengirimkan hasil dari Kawasan industri. Penentuan pusat pertumbuhan industri akan meningkatkan kualitas hidup masyarakat tempatan dan memastikan kondisi kehidupan yang berkelanjutan. Pengelompokan industri dapat meningkatkan pemanfaatan potensi pembangunan endogen dan integrasi masyarakat lokal. Oleh karena itu, pusat pertumbuhan industri mendukung pembangunan modal sosial lokal dan kualitas hidup. Penerapan pusat pertumbuhan dengan data multidimensi dalam studi kami melengkapi kesenjangan antara kebijakan pemerintah nasional dan daerah dengan masyarakat umum.

Kebijakan pusat pertumbuhan industri di Kabupaten Bengkalis bersinergi dengan adanya jalan tol Pekanbaru - Dumai. Kesemua akses pintu tol yang ada menuju pusat kegiatan nasional (PKN) Riau, yaitu pelabuhan Kota Dumai. Arahan lokasi-lokasi pelabuhan laut (umum) di WPPI Bengkalis, meliputi Sei Pakning-Buruk Bakul sebagai pelabuhan nasional dan Selat baru sebagai pelabuhan regional. Pengembangan poros transportasi Utara - Selatan menghubungkan pergerakan dari Duri - Buruk Bakul, dengan memanfaatkan jalur darat melalui jaringan jalan baru Duri - Sei Pakning, Buruk Bakul Bengkalis. Jalan tersebut terhubung penyeberangan Ro-Ro Sei Selari - Air Putih. Fokus pengembangan 
pada rencana kawasan industri Buruk Bakul, wilayah ini dilalui jalan provinsi Pekanbaru-Siak-Dumai. Kebutuhan air untuk kawasan industri bersumber dari sungai di sekitarnya.

\section{SARAN}

Studi yang dilakukan memungkinkan untuk merumuskan beberapa hal:

a. merancang wilayah pusat pertumbuhan di sekitar Buruk Bakul dengan akses langsung ke Pelabuhan dan ke Dumai.

b. sumber daya data spasial dan sosial ekonomi memungkinkan pengembangan analisis untuk mendukung kebijakan di daerah, model yang lebih rinci memerlukan pengembangan database baru dan studi terperinci.

c. lokasi klaster industri harus mendorong pembangunan daerah yang berkelanjutan, sehingga data potensi produksi bisa dieksplor sesuai keadaan daerah

\section{DAFTAR PUSTAKA}

[1] Derlukiewicz, N., Mempel-Śniezyk, A., Mankowska, D., Dyjakon, A., Minta, S., \& Pilawka, T. (2020). How do clusters foster sustainable development? An analysis of EU policies. Sustainability (Switzerland), 12(4). https://doi.org/10.3390/su12041297

[2] Gonzalez, A. V., Mack, E. A., \& Flores, M. (2017). Industrial complexes in Mexico: implications for regional industrial policy based on related variety and smart specialization. Regional Studies, 51(4), 537-547. https://doi.org/10.1080/00343404.2015.1114174

[3] Han, J. (2018). Integration and regional industrial development: Theoretical frameworks and literature reviews. Journal of China and International Relations, 6(1), 1-28.

[4] Harus, A. H., \& Zhuravliov, O. V. (2015). Application of the Theory of "Growth Poles" to the Economic Development of Ukraine. Effective Economy, 8, 338.1.

[5] Hunter, R. J., \& Saldana, G. (2013). The impact area of special economic zones: the effect of FDI on technology and knowledge transfer for native American reservations - a study of employment, innovation and absorptive capacity. Global Business and Economics Research Journal, 2(12), 1-28.

[6] Jacob, J., \& Hasan, N. (2016). Determining The Centers of Economic Growth And Regional Development Using Scalogram Analysis (An Empirical Study In West Halmahera Regency, Indonesia). IOSR Journal of Economics and Finance, 07(04), 31-36.

[7] Karmyshev, Y. A. (2005). On potential sources of development of Russia's Depressed Regions. Quality and FPI (CALS) Technologies, 1(1), 52-57.

[8] Lapaeva, M., \& Lapaev, S. (2020). Industrial Complex of the Orenburg Region: Challenges and Growth Prospects. 392(Eses 2019), 213-216. https://doi.org/10.2991/assehr.k.200113.043

[9] Lu, M. (2017). Urban, regional and national development: the present and future of spatial political economics. China Economic Quarterly, 16(4), 1499-1532. 
[10] Lyashenko, A. Y. (2015). Definition of points of economic growth of industrial region on the example of Dnepropetrovsk region. Economic Bulletin Donbass, 3(41), 91-101.

[11] Munyoka, W., \& Maharaj, M. (2017). The effect of UTAUT2 moderator factors on citizens' intention to adopt e-government: the case of two SADC countries. Problems and Perspectives in Management, 15(1), 115-123. https://doi.org/10.21511/ppm.15(1).2017.12

[12] Nijkamp, P. (2016). The «resourceful region». A new conceptualisation of regional development strategies. Investigaciones Regionales, 2016(36Specialissue), 191-214.

[13] Paramasatya, A., \& Rudiarto, I. (2020). Implikasi penetapan wilayah pusat pertumbuhan industri terhadap penggunaan lahan di Kabupaten Majalengka. Jurnal Pembangunan Wilayah Dan Kota, 16(2), 144-157. https://doi.org/10.14710/pwk.v16i2.22257

[14] Perroux, F. A. (1970). Note on the Concept of Growth Poles. In D. L. McKee, R. D. Dean, \& W. H. Leahy (Eds.), Regional Economics: Theory and Practice (pp. 93-103). Free Press.

[15] Pidgrushny, H. P. (2013). Importance of social-economic growth poles for the improvement of spatial social organization. Ukrainian Geographic Magazine, 4, 40-47.

[16] Pinem, D. E. (2016). Menemukan strategi pengembangan kawasan industri melalui analisis sektor unggulan Kota Binjai. Jurnal Wilayah Dan Lingkungan, 4(1), 45-64.

[17] Pysar, N. (2017). Application of the methodology for determining the "growth poles" of the region's industrial economy in the system of public administration. Problems and Perspectives in Management, 15(4), 72-85. https://doi.org/10.21511/ppm.15(4).2017.07

[18] Qiu, R., Xu, W., \& Zhang, J. (2015). The transformation of urban industrial land use: A quantitative method. Journal of Urban Management, 4(1), 40-52. https://doi.org/10.1016/j.jum.2015.07.001

[19] Rahayu, S., Warsono, H., \& Priyadi, B. P. (2019). Factors the Development of Region Promotion Activities Centre (PKWp) in Lebak District Banten Province. Jurnal Ilmiah Ilmu Administrasi Publik, 9(1), 111. https://doi.org/10.26858/jiap.v9i1.9352

[20] Rianto, I. B., \& Santoso, E. B. (2018). Penentuan lokasi kawasan industri tekstil terpadu di Kabupaten Majalengka. Jurnal Teknik ITS, 7(1), C19-C23.

[21] Rozaki, Z. (2020). Decrease of agricultural land and industry growth in Special Region of Yogyakarta. IOP Conference Series: Earth and Environmental Science, 458(1).

[22] Szewrański, S., Bochenkiewicz, M., Kachniarz, M., Kazak, J. K., Sylla, M., Świąder, M., \& Tokarczyk-Dorociak, K. (2019). Location support system for energy clusters management at regional level. IOP Conference Series: Earth and Environmental Science, 354(1).

[23] Yang, Z., Song, T., \& Chahine, T. (2016). Spatial representations and policy implications of industrial co-agglomerations, a case study of Beijing. Habitat International, 55, 32-45. 